\title{
Five New Universal Public Health.....
}

\section{Best Mouth Hygiene}

Almost all contagious diseases from Strep Throat to viruses infect through the mouth--especially the gums (In fact, most likely all diseases have something to do with what we inhale or ingest). Basically, a clean mouth means strong gums which means better health. Teeth should be brushed twice a day--morning and bedtime with flossing before each time. Flossing firmly strengthens the gums. Teeth, gums and tongue need brushing, especially the gums which need massaging to stay firm and strong. The vibrating toothbrushes are best and give a 2 minute hygienic cleansing better than any manual brushing. The cost is readily covered by money saved on medications and less than the electronic game gadgets everyone has. Mouth hygiene means not putting garbage into your mouth: Keep hands clean; avoid cigarettes, marihuana, inhalants, snorts, street drugs, or anything unclean. Keep everything about and in your mouth clean and your gums strong. Mouth gargling and rinsing several times a day with a favorite over-the-counter mouthwash and/or occasionally with strong salt water solution (salt water kills most germs) is recommended. Finally, "best breathing" by the nose strengthens the mouth gums also by lessening gum dryness, and the nose is both a barrier and expeller of negative inhalants.

\section{Best Breathing}

Make No Mistake, there is a "best" way to breath. "Nasal inhalation" is the best way--It is more diaphragmatic requiring less muscle effort and thus more of the inhaled oxygen is used elsewhere in the body. However, "shutting your mouth" is obligatory for efficient and effective "nasal breathing"--laryngeal reflexes open better with "air into the nose" than with "air into the mouth." Mouth closure while breathing prevents dryness of mouth mucous membranes which work best when moist. A dry mouth because of mouth breathing does not protect well. Snoring dries the mouth, so practice sleeping by nasal inhaling and exhaling with shut mouth is essential. Choking basically is the erroneous intermingling of inhaling and swallowing which can be prevented and corrected by nasal breathing. Learn and practice the acronym "SAM": Shut mouth; Air in nose; Mouth cough (if choking or clearing throat) or just exhale (by mouth or preferably nose). The SAM must be practiced--it does not come naturally for most. Learn, practice, and teach the SAM--you will be "best breathing." (By the way, the SAM works as a panic/ temper/rage/confusion stopping technique by detachment from the source of emotionality to calmer self-awareness and improved oxygenation--"Just do the SAM and think it through.")

\section{Best Coughing}

Coughing is the body's way of expelling something unwanted. To make a cough more effective, do the SAM! First Shut the mouth, then inhale nasally as deeply as you can, and then really explode a mouth cough into your kerchief or elbow. That really should be

\author{
Opinion \\ Volume 6 Issue 1 - 2016 \\ Dr. Samuel A Nigro M.D* \\ Retired, Assistant Clinical Professor Psychiatry, Case Western \\ Reserve University School of Medicine, USA \\ *Corresponding author: Dr. Samuel A Nigro M.D, Retired, \\ Assistant Clinical Professor Psychiatry, Case Western Reserve \\ University School of Medicine, 2517 Guilford Road, Cleveland \\ Heights, Ohio 44118, USA, Tel: 216 932-0575; Email: \\ sam@docnigro.com
}

Received: November 11, 2015 | Published: June 02, 2016

done as personal health measure twice daily for 3 coughs after brushing your teeth each time. This cleans your lungs. If you feel a chest cold coming on, do it several more times whenever. It can help prevent the chest cold and can keep you healthier.

\section{Best Knee \& Back Exercises}

Walk $50+$ steps on your heels; or rock back and forth from one heel to the other. The paraspinal muscles and hip ab \& ad -ductors are all tightened by walking on your heels. You will be surprised how the aches and pains often disappear after consistent heel walking (or rocking). The paraspinal muscles especially do not get exercised and it seems that the spinal cord system works better with stronger paraspinal muscles. I discovered this during my recovery from bilateral simultaneous knee replacements. It worked and I found heel walking helped whenever I have had knee or back aches ever since.

\section{Saving Teeth}

This is my one time experience. Wisdom teeth extracted as young adult, so, at 78 years old, my lower left 2 nd molar begins to throb and hurt. The dentist checks with xrays finding nothing but recommends someone for extraction--"This is what is regularly done to relieve the pain and discomfort" (which I knew because of relatives' having many such extractions). However, the dentist did give me a trial of penicillin and higher fluoride toothpaste which did not work after two weeks. But I thought that the antibiotic by pills would never get concentrated about that tooth, so I bought topical triple antibiotic cream. I squeezed a little high fluoride toothpaste and the topical antibiotic on my finger and massaged them onto and around my hurting tooth. I did this after tooth brushing morning and night. My tooth cleared up and it has been 8 months with normal painless functioning. I still do the toothpaste/antibiotic massage every morning. It is merely one case, but it is so simple, inexpensive and it is still working! Perhaps it is worth trying. 